\title{
Polydactyly of an index finger
}

INSERM

\section{Source}

INSERM. (1999). Orphanet: an online rare disease and orphan drug data base. Polydactyly of an index finger. ORPHA:93337

Polydactyly of an index finger or PPD3 is a form of preaxial polydactyly of fingers (see this term), a limb malformation syndrome, where the thumb is replaced by one or two triphalangeal digits with dermatoglyphic pattern specific of the index finger. Two forms of PPD3 have been characterized: unilateral and bilateral (see these terms). There have been no further descriptions in the literature since 1962. 